\title{
Activity of Antimicrobial Silver Polystyrene Nanocomposites
}

\author{
M. Palomba, ${ }^{1}$ G. Carotenuto, ${ }^{1}$ L. Cristino, ${ }^{2}$ M. A. Di Grazia, ${ }^{2}$ F. Nicolais, ${ }^{3}$ and S. De Nicola ${ }^{4,5}$ \\ ${ }^{1}$ Istituto per i Materiali Compositi e Biomedici, CNR, Piazzale Tecchio 80, 80125 Napoli, Italy \\ ${ }^{2}$ Istituto di Cibernetica, CNR, Via Campi Flegrei 34, 80078 Pozzuoli, Italy \\ ${ }^{3}$ Dipartimento di Scienze Politiche, Sociali e della Comunicazione, Università degli Studi di Salerno, Via Ponte don Melillo, \\ 84084 Fisciano, Italy \\ ${ }^{4}$ Istituto Nazionale di Ottica, CNR, Via Campi Flegrei 34, 80078 Pozzuoli, Italy \\ ${ }^{5}$ INFN Sezione di Napoli, Via Cintia (Complesso Monte S. Angelo), 80126 Napoli, Italy
}

Correspondence should be addressed to S. De Nicola, sergio.denicola@ino.it

Received 24 June 2012; Accepted 22 October 2012

Academic Editor: Kin Tak Lau

Copyright ( $) 2012$ M. Palomba et al. This is an open access article distributed under the Creative Commons Attribution License, which permits unrestricted use, distribution, and reproduction in any medium, provided the original work is properly cited.

A simple technique based on doping polymers with in situ generated silver nanoparticles (Ag/PS films) has been developed. In particular, an antiseptic material has been prepared by dissolving silver 1,5-cyclooctadiene-hexafluoroacetylacetonate in amorphous polystyrene, and the obtained solid solution has been heated for ca. $10 \mathrm{~s}$ at a convenient temperature $\left(180^{\circ} \mathrm{C}\right)$. Under such conditions the metal precursor decomposes producing silver atoms that diffuse into the polymer and clusterize. The antimicrobial characteristics of the resulting polystyrene-based material have been accurately evaluated toward Escherichia coli (E. coli) comparing the cytotoxicity effect of $10 \mathrm{wt} . \%$ and $30 \mathrm{wt} . \%$ (drastic and mild annealing) silver-doped polystyrene to the corresponding pure micrometric silver powder. Two different bacterial viability assays were performed in order to demonstrate the cytotoxic effect of Ag/PS films on cultured E. coli: (1) turbidimetric determination of optical density; (2) BacLight fluorescencebased test. Both methods have shown that silver-doped polystyrene (30 wt.\%) provides higher antibacterial activity than pure Ag powder, under similar concentration and incubation conditions.

\section{Introduction}

In recent years noble metal nanoparticles have been the subjects of many researches due to their unique electronic, optical, mechanical, magnetic, and chemical properties significantly different from those of bulk materials [1]. These special and unique properties could be attributed to the small size and the large specific surface area characterizing these systems. For such reasons metallic nanoparticles have found applications in a variety of technological fields as catalysis, electronics, and photonics [1]. Polymer-embedded metal nanoparticles represent a very simple and convenient way to use such nanostructures and some chemical and physical techniques are now available for preparing these materials, the most important approaches are usually based on the in situ thermolysis of metal precursors [2].

Nanoparticles of silver have been found to exhibit interesting antibacterial activities [3, 4], and the investigation of this phenomenon has gained importance due to the increase of bacterial resistance to antibiotics, caused by their overuse.
Recently, there have been developed materials (mainly textiles) containing silver nanoparticles, which exhibit very interesting antimicrobial activity. Antibacterial activity of the plastic-containing silver can be used, for example, in medicine to reduce infections as well as to prevent bacteria colonization on plastic devices like: prostheses, catheters, vascular grafts, dental materials, and so forth [5]. Under proper temperature and humidity conditions, plastics can be a good medium for the generation and the propagation of microorganisms which can cause irritations and infections. For these reasons, the polymeric materials must be protected against microorganisms in order to suppress their growth and dissemination. Owing to the high antimicrobial activity, relatively low cost, and easy production in a polymer-embedded form, nanoscopic silver could be a very adequate filler for such a purpose [6-8]. Silver nanoparticles is one of non-toxic and safe wide-range antibacterial agents to the human body, able to kill most harmful microorganisms. The mechanism of antibacterial action of silver ions is closely related to their interaction with proteins, particularly at thiol groups 


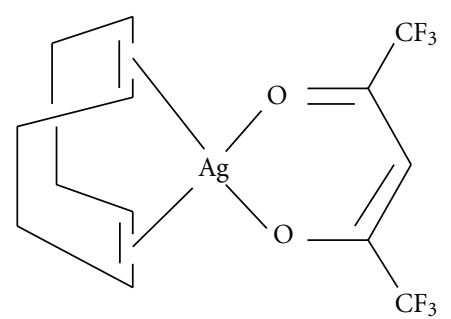

Figure 1: Chemical structure of the $[\mathrm{Ag}(\mathrm{hfac})(\mathrm{COD})]$ molecule.

(sulfydryl, $-\mathrm{SH}$ ), and are believed to bind protein molecules together by forming bridges along them. Since the proteins behave often like as enzymes, the cellular metabolism is inhibited and the microorganism dies. Considering that the atomic radius $r$ of the silver is much smaller than the radius $R$ of a nanoparticle, it is possible to calculate the fraction of surface silver atoms according to the simple relationship $6 r / R$. Therefore, the number of surface silver atoms increases with decreasing the dimension of the nanoparticle and this, in turn, leads to an enhancement of the antibacterial ability of each nanoparticle $[3,4]$.

The purpose of this research is to study the antimicrobial characteristics of a silver-polystyrene nanocomposite system. Such advanced material has been prepared by a new chemical approach based on the thermolysis of a silver precursor dissolved in polymer. Noble-metal nanoparticles can be uniformly generated into a thermoplastic polymer by controlled thermal decomposition of a metallorganic precursor dissolved in it $[9,10]$. Here, silver 1,5-cyclooctadienehexafluoroacetylacetonate, $[\mathrm{Ag}(\mathrm{hfac})(\mathrm{COD})]$ (see Figure 1), has been used to generate silver nanoparticles into amorphous polystyrene. This special organic compound thermally decomposes at a temperature of ca. $150^{\circ} \mathrm{C}$, which is compatible with thermal stability of most thermoplastic polymers [11]. In addition, $[\mathrm{Ag}(\mathrm{hfac})(\mathrm{COD})]$ is characterized by an excellent solubility in nonpolar polymers and solvents, and consequently nanocomposites with a very high numerical density of silver nanoparticles can be prepared by using such compounds as silver precursor. According to the obtained results, an effective antimicrobial plastic results by thermally decomposing $[\mathrm{Ag}(\mathrm{hfac})(\mathrm{COD})]$ in molten polystyrene, probably because of the large amount of nanoscopic silver present on the polymer surface. Silver nanoparticles dispersed in thin coating layers of thermoplastic polymer binders can be advantageously used for their antimicrobial activity in varnishes, paints and inks. The bactericidal action of these nanoparticles can also be used in polymeric fibers produced by electrospinning and in other types of fibers, such as hollow fibers.

\section{Experimental}

2.1. Preparation and Characterization of the Ag/PS Films. Silver 1,5-cyclooctadiene-hexafluoroacetylacetonate $\left(\mathrm{C}_{13} \mathrm{H}_{13} \mathrm{AgF}_{6} \mathrm{O}_{2}\right.$, Aldrich, 99\%) was purified by recrystallization from chloroform. $[\mathrm{Ag}(\mathrm{hfac})(\mathrm{COD})] /$ polystyrene solid solutions were prepared by dissolving the $[\mathrm{Ag}(\mathrm{hfac})(\mathrm{COD})]$ microcrystalline powder in chloroform and then mixing it with a viscous solution of amorphous polystyrene (Aldrich, $M_{w}=230,000 \mathrm{gmol}^{-1}$ ) in chloroform. In order to investigate the dependence of nanocomposite antimicrobial properties on the nanoparticle concentration, different $[\mathrm{Ag}(\mathrm{hfac})(\mathrm{COD})] /$ polystyrene samples with compositions ranging from 1 to $30 \%$ by weight of $[\mathrm{Ag}(\mathrm{hfac})(\mathrm{COD})]$ were prepared. The high solubility of silver 1,5-cyclooctadiene-hexafluoroacetylacetonate in amorphous polystyrene at room temperature allows us to prepare nanocomposite systems with quite large amounts of silver nanoparticles without formation of silver aggregates. The obtained liquid solutions were cast onto a Petri dish and allowed to dry in air at $25^{\circ} \mathrm{C}$ for $48 \mathrm{~h}$. Then, nanocomposite films were produced by isothermally heating the dry $[\mathrm{Ag}(\mathrm{hfac})(\mathrm{COD})] /$ polystyrene systems onto a laboratory hot-plate at a temperature of $180^{\circ} \mathrm{C}$. The precursor $[\mathrm{Ag}(\mathrm{hfac})(\mathrm{COD})] /$ polystyrene films were transparent and colorless, but during the controlled thermal annealing treatment a yellow coloration of the films was developed that evolved to brown by increasing the precursor concentration (a silvery aspect was observed at higher concentrations).

2.2. Bacterial Culture and Viability Assays. The original culture of E. coli was made in sterile lysogeny broth LB (Invitrogen Life Coporation, California, USA) in sterile tubes at starting dilution of $10^{-2}$ and incubated over $24 \mathrm{~h}$ at $37^{\circ} \mathrm{C}$ under gently agitation. Therefore, $1 \mathrm{~mL}$ of this starting culture was transferred in $9 \mathrm{~mL}$ of fresh broth in triplicate sampling, for each of the treatments summarized in Table 1 $(\mathrm{A}-\mathrm{F})$, over $16 \mathrm{~h}, 24 \mathrm{~h}$ and $48 \mathrm{~h}$ incubation at $37^{\circ} \mathrm{C}$ under gently agitation.

By spectrophotometric analysis the increased turbidity of the reading reflects the index of bacterial growth and cell numbers (biomass) and the amount of transmitted light decreases as the cell population increases. The absorbance, or optical density (O.D.), was read at wavelength $540 \mathrm{~nm}$ and it gives an indirect measurement of the number of $E$. coli. To this purpose, the absorbance of $1 \mathrm{~mL}$ of each specimens was measured by the spectrophotometer (Biorad, Denmark). The spectrophotometric measurement was made by standardizing the machine on the sterile nutrient broth with its concentration equal to zero.

The spectrophotometric measurements were performed at $16 \mathrm{~h}, 24 \mathrm{~h}$, and $48 \mathrm{~h}$ of incubation with different composition of Ag/PS films, and they were repeated for each treatment (A-F in Table 1).

This spectrophotometric analysis was paralleled by the live/dead BacLight Bacterial Viability assay for microscopy (Invitrogen Life Coporation, California, USA) which allows fast and high sensitive, qualitative and quantitative, monitoring of bacterial viability as a function of the membrane integrity of the cell. This method is based on two nucleic acid stains: green fluorescent SYTO 9 stain and red fluorescent propidium iodide stain which differ in their ability to penetrate healthy bacterial cells. SYTO 9 stain labels live bacteria, in contrast propidium iodide penetrates only bacteria with damaged membranes. Quantitative analysis was performed by cell-counting Bürker chamber on live/dead stained bacterial culture after $16 \mathrm{~h}, 24 \mathrm{~h}$, and $48 \mathrm{~h}$ of $\mathrm{Ag} / \mathrm{PS}$ 
TAble 1: Time-dependent antiseptic evaluation of Ag/PS films. Spectrophotometric lecture of the optical density (O.D.) in E. coli culture shows significant $\left({ }^{*} P \leq 0.05\right)$ antibacterial effect after $24 \mathrm{~h}$ and $48 \mathrm{~h}$ of incubation with $\mathrm{Ag} / \mathrm{PS}$ films, both at mild and drastic annealing, compared to blank.

\begin{tabular}{|c|c|c|c|}
\hline Samples (E. coli culture) & 16 h O.D. & 24 h O.D. & 48 h O.D. \\
\hline (A) Blank, without Ag/PS film & 0.855 & 1.003 & 1.205 \\
\hline (B) +10 wt. $\%$ Ag/PS film $1 \mathrm{~cm} \times 1 \mathrm{~cm} \mathrm{0,0150} \mathrm{mg}$ & 0.774 & 0.898 & 0.939 \\
\hline $\begin{array}{l}\text { (C) }+30 \text { wt. } \% \text { Ag/PS film } 1 \mathrm{~cm} \times 1 \mathrm{~cm} 0,0177 \mathrm{mg} \\
\text { drastic annealing }\end{array}$ & 0.687 & $0.815\left({ }^{*} P \leq 0.05\right)$ & $0.742\left({ }^{* *} P \leq 0.001\right)$ \\
\hline $\begin{array}{l}\text { (D) }+30 \text { wt. } \% \text { Ag/PS film } 1 \mathrm{~cm} \times 1 \mathrm{~cm} 0,0177 \mathrm{mg} \\
\text { mild annealing }\end{array}$ & 0.786 & $0.822(* P \leq 0.05)$ & $0.862\left({ }^{*} P \leq 0.05\right)$ \\
\hline (E) $+0.009 \mathrm{mg}$ pure Ag powder & $0.591(* P \leq 0.05)$ & $0.722(* P \leq 0.05)$ & $0.891\left({ }^{*} P \leq 0.05\right)$ \\
\hline (F) $+0.007 \mathrm{mg}$ pure Ag powder & $0.656(* P \leq 0.05)$ & 0.890 & 1.056 \\
\hline
\end{tabular}

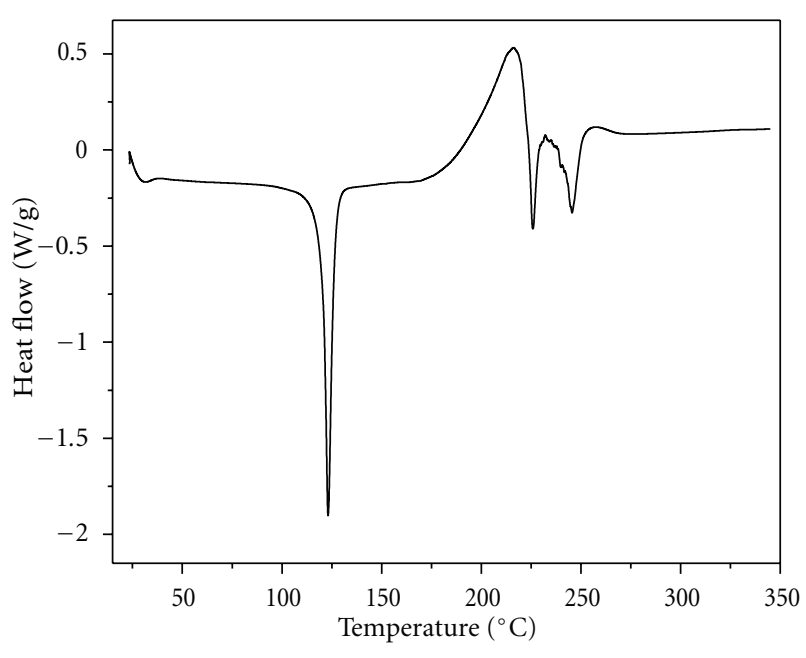

FIGURE 2: DSC thermogram of a pure $[\mathrm{Ag}(\mathrm{hfac})(\mathrm{COD})]$ sample.

films incubation compared to blank and Ag pure powder treatments. The results were expressed as percentage of live or dead bacteria calculated on the total number of cells.

\section{Results and Discussions}

The minimum temperature value required for $[\mathrm{Ag}(\mathrm{hfac})(\mathrm{COD})]$ thermal decomposition was established by differential scanning calorimetry (DSC, TA-Instrument Q100) and thermogravimetric analysis (TGA, TA-Instruments Q500) performed on the pure compound. As visible in Figure 2, this organic salt melts at $110^{\circ} \mathrm{C}$ and, according to the TGA test, it simultaneously decomposes, loosing the 1,5-cycloocatadiene (COD) ligand. Then, the decomposition of the $\mathrm{Ag}(\mathrm{hfac})$ fragment follows, this process is strongly exothermal and starts at ca. $150^{\circ} \mathrm{C}$. The exothermal peak is deformed by the simultaneous evaporation of the thermolysis byproducts which is an endothermal phase transition. In fact, according to the thermogravimetric analysis performed in air at $10 \% \mathrm{~min}$ (see Figure 3), weight loss of organic byproduct is visible at $150^{\circ} \mathrm{C}$, and a residual weight of $25 \%$, which exactly corresponds to the formation of zero-valent silver, resulted.

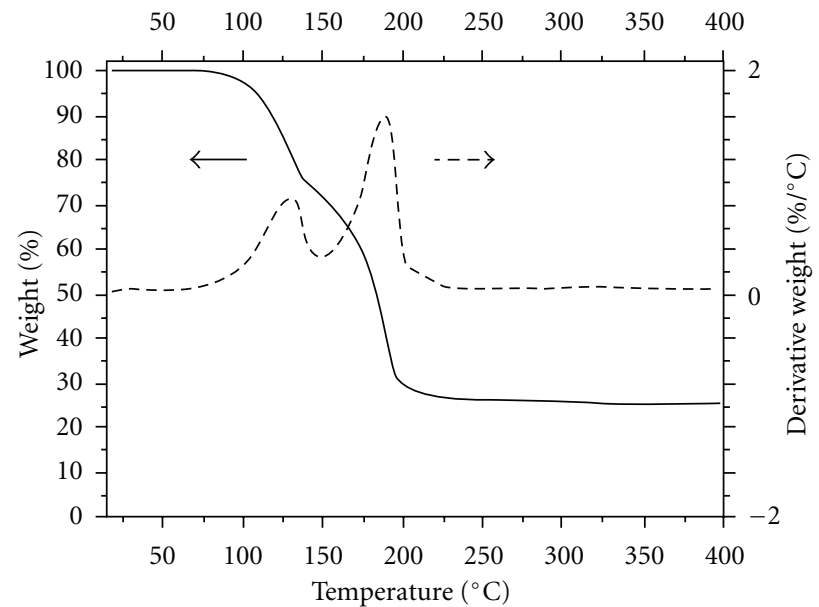

Figure 3: TGA and DTGA thermograms of a pure $[\mathrm{Ag}(\mathrm{hfac})(\mathrm{COD})]$ sample.

The formation of a zero-valent silver nanoscopic phase by the thermal decomposition of $[\mathrm{Ag}(\mathrm{hfac})(\mathrm{COD})]$ dissolved in amorphous polystyrene was confirmed by large-angle X-ray powder diffraction (XRD) analysis. In particular, the main peak in the XRD diffractogram shown in Figure 4 corresponds to (111) signal of the ccp-silver diffraction pattern. Owing to the nanoscopic silver size, a quite low signal to noise ratio characterizes the XRD diffractogram. Therefore, pure $[\mathrm{Ag}(\mathrm{hfac})(\mathrm{COD})]$ resulted quantitatively converted to zero-valent silver by the performed thermal treatment.

The TEM and SEM micrographs shown in Figure 5 represents the typical microstructure of a Ag/PS nanocomposite sample. In particular, the sample was obtained by annealing an $[\mathrm{Ag}(\mathrm{hfac})(\mathrm{COD})] /$ polystyrene film $(30 \%$ by weight of $[\mathrm{Ag}(\mathrm{hfac})(\mathrm{COD})])$ for $10 \mathrm{~s}$ at $180^{\circ} \mathrm{C}$. Pseudospherical and quite monodispersed silver nanoparticles, of ca. $7 \mathrm{~nm}$, appear to be homogeneously distributed into the continuous polystyrene matrix. In addition, a large amount of very small silver nanoparticles $(\mathrm{ca} .3 \mathrm{~nm}$ ) were present everywhere over the sample. According to the SEM micrographs, silver nanoparticles were present also at surface of the silver/polystyrene nanocomposite. 


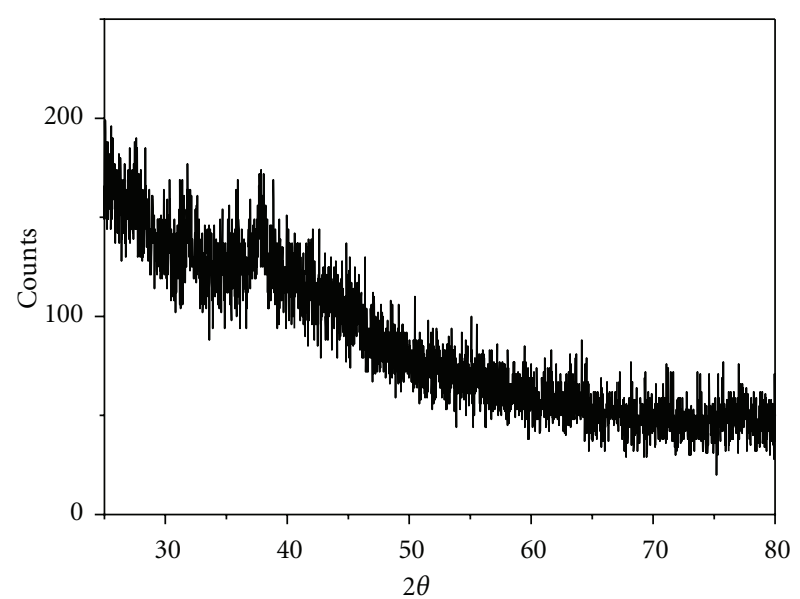

FIGURE 4: XRD of Ag/PS nanocomposite obtained by thermally decomposing $[\mathrm{Ag}(\mathrm{hfac})(\mathrm{COD})]$ dissolved in polystyrene.

Differently from the use of thiolates as thermolytic precursor for the in situ generation of metal nanoparticles into an amorphous polymer matrix [2], the silver 1,5cyclooctadiene-hexafluoroacetylacetonate precursor originates nanoparticles with a larger average particle size. Probably, such a behavior is related to the presence of a capping agent (i.e., hexafluoroacetylacetonate molecules) less effective than the sulfur-containing molecules (e.g., disulfide) present in the thiolate precursor thermal decomposition.

A UV-Vis spectrophotometer (PerkinElmer, Mod. Lambda 850) was employed to study the surface plasmon resonance of the polymer-embedded silver nanoparticles obtained at low concentration of precursor. Figure 6 shows the extinction spectrum of an $[\mathrm{Ag}(\mathrm{hfac})(\mathrm{COD})] /$ polystyrene film $(30 \%$ by weight of $[\mathrm{Ag}(\mathrm{hfac})(\mathrm{COD})])$. An approximately Gaussian-shaped peak characterized the surface plasmon absorption of the silver nanoparticle dispersion into the dielectric polystyrene matrix, which is attributed to a nonaggregated dispersion of nanoparticles for different precursors content (thermal annealing of $10 \mathrm{~s}$ at $180^{\circ} \mathrm{C}$ ).

The antibacterial activity of a small piece of silverpolystyrene film is summarized in Table 1. Ag nanoparticles are present at film surface and therefore they can release silver ions in the environment where they are placed, while $[\mathrm{Ag}(\mathrm{hfac})(\mathrm{COD})]$ has been completely converted into gaseous products $\left(\mathrm{COD}, \mathrm{CO}_{2}, \mathrm{H}_{2} \mathrm{O}\right.$, etc.) and silver. In order to investigate the dependence of the antibacterial activity on the silver nanoparticle concentration, two different $[\mathrm{Ag}(\mathrm{hfac})(\mathrm{COD})] / \mathrm{PS}]$ nanocomposites containing 30\% by weight of precursor have been tested: the first, obtained by using a mild thermal annealing treatment $\left(20 \mathrm{~s}\right.$ at $\left.150^{\circ} \mathrm{C}\right)$, and the second obtained by a drastic thermal annealing treatment $\left(60 \mathrm{~s}\right.$ at $\left.150^{\circ} \mathrm{C}\right)$.

The antiseptic properties were evaluated by spectrophotometric lecture of the optical density (O.D.) measured at standard wavelength $(540 \mathrm{~nm})$, using a fixed volume of Escherichia coli suspension culture, continuously stirred up to $16 \mathrm{~h}, 24 \mathrm{~h}$, and $48 \mathrm{~h}$ of incubation. Table 1 reports the O.D. values of the bacteria incubated with different Ag/PS nanocomposite samples at different time $(16 \mathrm{~h}, 24 \mathrm{~h}$, and $48 \mathrm{~h}$ ), the O.D. value of a blank sample (i.e., bacteria culture without the Ag/PS film), and the values of bacteria culture incubated with pure metallic silver powder at different concentrations.

From data reported in Table 1 it is visible as the O.D. of samples incubated with plastic films is less than that of the blank sample and only slightly less than that of the same sample incubated with two different concentrations of pure silver. This behavior confirmed the good antibacterial activity of such nanocomposite material. It can be also seen that the O.D. of the blend films decreased with the increasing of the silver content, owing to the increase of the antibacterial activity with the Ag nanoparticles content.

Sample containing the same percentage by weight of silver precursor (30 wt.\%), obtained after a drastic annealing treatment, exhibited higher antibacterial properties compared to that obtained after a mild annealing treatment.

Furthermore, from the experimental O.D. data at $24 \mathrm{~h}$ and $48 \mathrm{~h}$ of incubation, a value of statistical significance $P \leq$ 0.05 was obtained for the sample of Ag/PS (30\% of precursor, mild annealing) and for the sample incubated with $0.009 \mathrm{mg}$ of pure Ag powder. The statistical significance was improved $(P \leq 0.001)$ for sample of Ag/PS (30\% weight of precursor, drastic annealing).

Furthermore, in order to investigate on the existence of a faster Ag/PS antibacterial action we performed qualitative and quantitative evaluation of Ag/PS activity for each of the treatments (A-E in Table 1 ) after $16 \mathrm{~h}$ incubation.

To this purpose we exploited the highly sensitive qualitative and quantitative Bacterial Viability LIVE/DEAD BacLight assay for fluorescence microscope [12]. This method is based on the combined ability of the membranepermeant SYTO 9 to label live bacteria with green fluorescence and membrane-impermeant propidium iodide to label membrane-compromised bacteria with red fluorescence. This procedure was performed for each Ag/PS treatment and the antimicrobial effects were analyzed by Leica DMI6000 epifluorescence microscope using appropriate emission filters.

The images were acquired using a digital camera (Leica DFC420 and data analysis was performed using the Leica MM AF Analysis Offline software (Leica, Germany). Following the procedure described in [13], the quantitative analysis of loss cell viability was calculated by the ratio of dead on live cells counted in the Burker chamber. The data were expressed as mean of percentage \pm s.d.m. and a repeated two-way ANOVA was performed using SPSS version 8.2. Student's or Bonferroni two-tail $t$-test was used to judge statistical significance between groups $(P<0.05)$.

The image shown Figure 7 (a) was recorded after $16 \mathrm{~h}$ of incubation in presence of the liquid medium for bacteria growth (LB). It clearly displays a persistent green fluorescence extended to the entire bacteria culture. However, the system results significantly modified in the case of bacteria culture incubated with plastic film of Ag/PS (30\% by weight of precursor, mild thermal annealing).

Indeed, Figure 7 (c) recorded after $16 \mathrm{~h}$ of incubation, shows that almost all the bacteria are red colored with a very little number of green-colored cells. These qualitative effects were confirmed by quantitative analysis of antimicrobial 


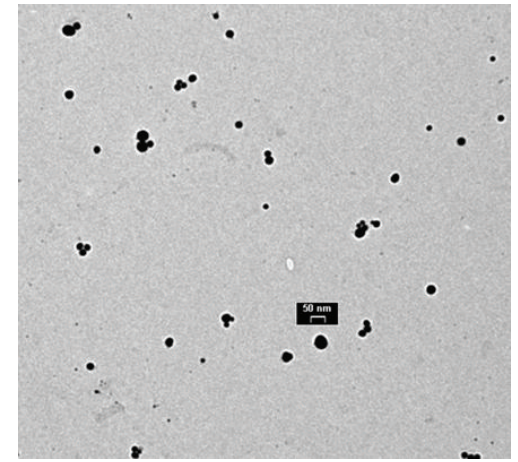

(a)

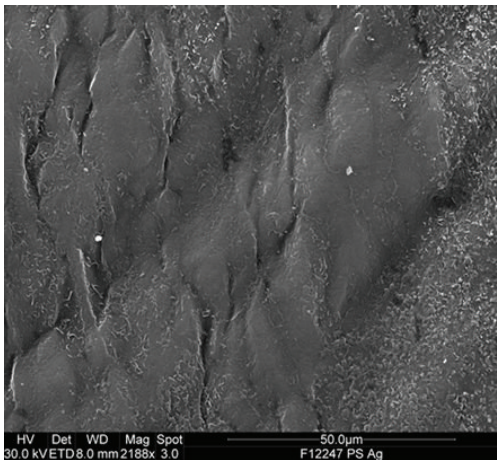

(c)

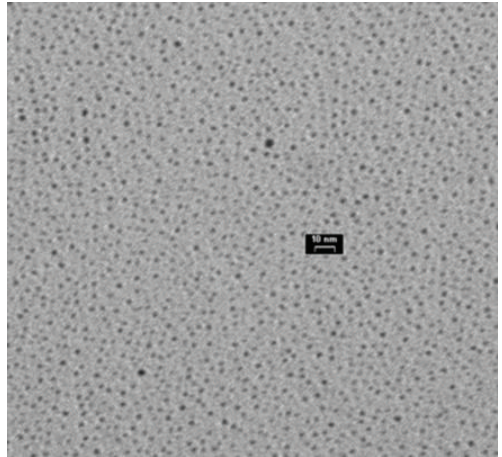

(b)

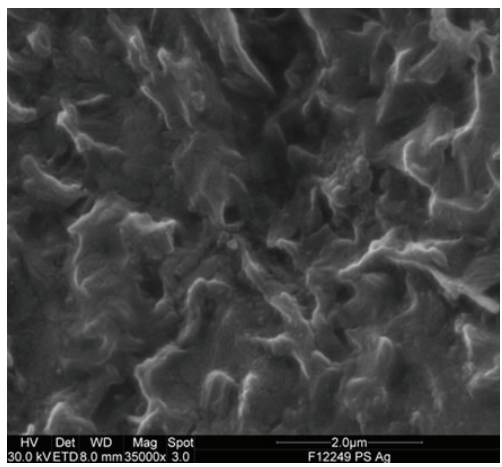

(d)

FIGURE 5: TEM and SEM micrographs of a nanocomposite sample. As visible, the silver particles are present also at film surface.

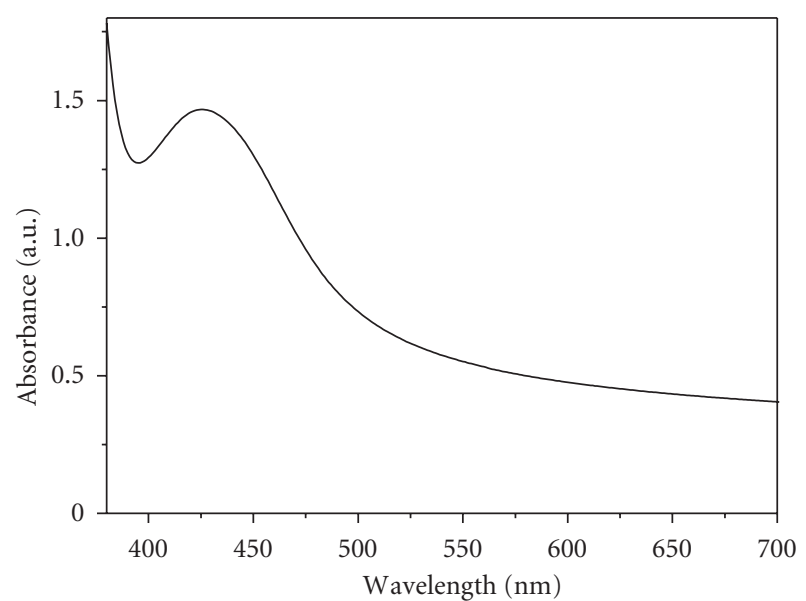

Figure 6: Optical spectrum of $[\mathrm{Ag}(\mathrm{hfac})(\mathrm{COD})] / \mathrm{PS}$ film of different compositions.

properties. The corresponding results, summarized in Figure 7(b) indicate an intense loss of \% E. coli viability after mild and drastic thermal annealing with $30 \%$ by weight of precursor.

Similar effect was found in pure Ag powder, which is in good agreement with the data obtained by the spectrophotometric O.D. technique. However, the sensitivity of this method is lower and it shows a significant antimicrobial effect only after $24 \mathrm{~h}$ of aging time of the Ag/PS sample.
The antibacterial activity of a zero-valent silver phase is strictly depending on the surface development of the solid, since silver atoms/ions required to accomplish the antibacterial activity are released only from the surface. Consequently, when this solid phase is in a powdered form, the resulting antibacterial activity can be significantly increased and an ultrafine silver powder may result in several orders of magnitude more activity than the corresponding bulksolid. Therefore, the incorporation of nanosized silver (silver clusters or nanoparticles) into a plastic material should represent the best choice to fabricate materials devoted to such a technological application.

To investigate the influence on the antibacterial activity of a silver atom distribution, a simple geometrical model based on a silver particle of radius $R$, and an atom of radius $r \ll R$ can be considered. Then, it is possible to calculate the number of surface silver atoms according to the simple relation: $4 R^{2} / r^{2}$ which corresponds to the fraction $6 r / R$ (percentage of surface silver atoms). These simple considerations show that the fraction of surface silver atoms increases with decreasing of size of the particle and that we may assume that all atoms in a nanosized powder are practically on the surface. All atoms in a hyperfine powder are, to a good approximation, available for the antibacterial activity because they can leave the particle and move to the sulphured groups (i.e., sulfhydryls $-\mathrm{SH}$, and, disulfides $-S-S-)$ present in the proteins of the microbe cellular membrane. 


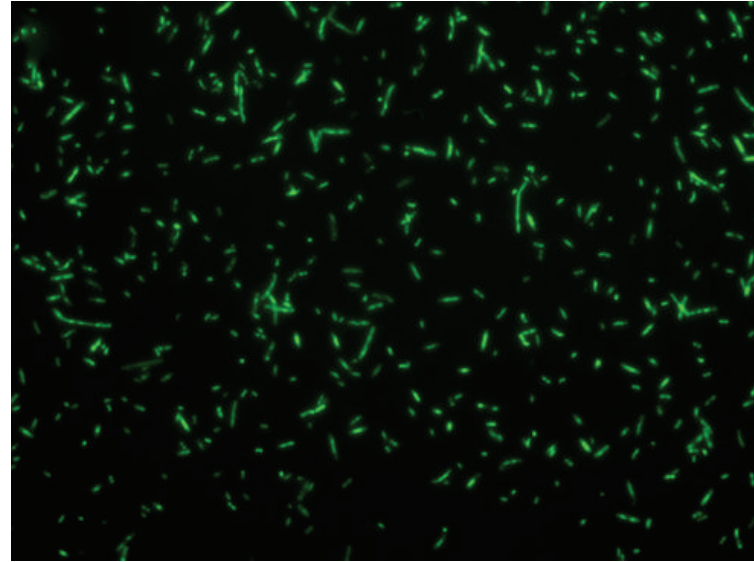

(a)

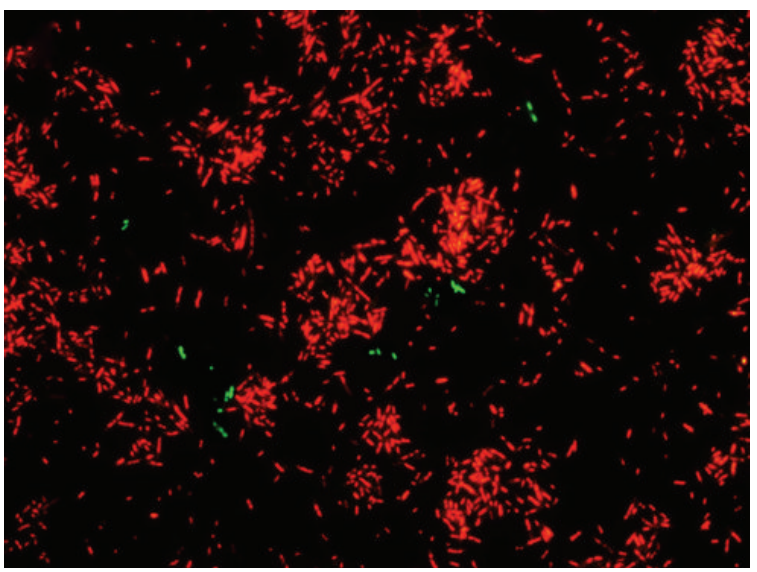

(c)

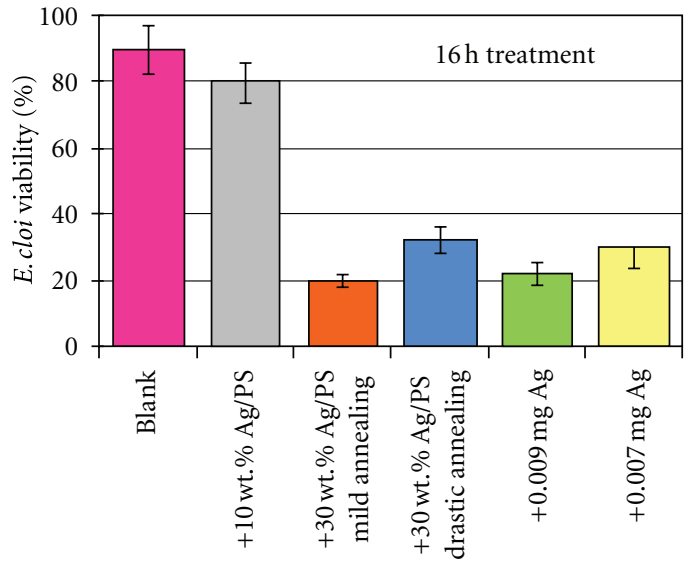

(b)

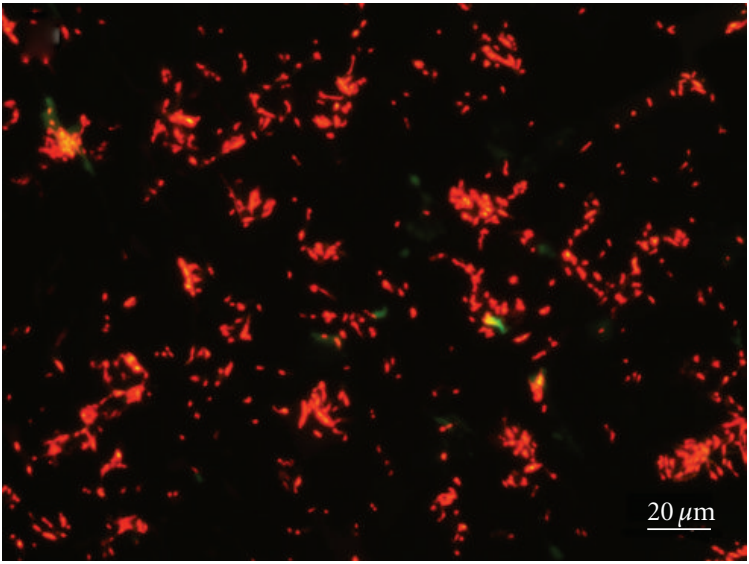

(d)

FIGURE 7: Live-dead cell staining assay: microscopic analysis and quantitative evaluation. (a) High number of green-labeled living bacteria after $16 \mathrm{~h}$ incubation in LB, without Ag/PS. (c), (d): high number of red-labeled dead bacteria after $16 \mathrm{~h}$ incubation $+30 \mathrm{wt} . \% \mathrm{Ag} / \mathrm{PS}$ film $(1 \mathrm{~cm} \times 1 \mathrm{~cm}-0.0177 \mathrm{mg})$ obtained by using a mild thermal annealing treatment (c); similar results were observed in bacteria culture after $16 \mathrm{~h}$ of incubation with Ag powder (d). Scale bar represents $20 \mu \mathrm{m}$. (b) Quantitative analysis of the E. coli viability (\%) after $16 \mathrm{~h}$ incubation at each condition reported in Table 1 (A-E).

Actually the silver atoms are arranged in a cubic crystal and a more detailed analysis should also take into account the coordination numbers of the atoms in the crystal edges, corners, and those located at the basal planes. The coordination numbers are 3, 4, and 5 for the atoms in the crystal edge, corner, and basal plane, respectively. If we assume a cubic crystal of dimensions $L$ and a lattice constant much less than $L$, simple dimensional considerations show that the fraction of atoms in the crystal edge and corners increases with decreasing of the size $L$ of the particle compared to the fraction of atoms at the basal planes. This means that the atoms in the crystal edge and corner can leave the crystal surface more easily and diffuse in the surrounding liquid medium where microbes and other microorganisms are contained and that this tendency is enhanced in a nanosize particle compared to a larger one.

Finally, the nanosized silver antibacterial activity is enhanced for two main reasons: (i) the fraction of surface silver atoms increases with decreasing the particle size, and (ii) a greater fraction of surface silver atoms weakly bonded to the particle surface that can be easily released in the surrounding medium.

The Ag/PS nanocomposite antimicrobial activity is basically related to its ability to release $\mathrm{Ag}^{+}$during the time. Because silver nanoparticles are embedded in a continuous polystyrene matrix, the temporal evolution of the antimicrobial activity depends on the stability of the metal cluster into the matrix.

Since the silver nanocrystals are well anchored to the embedding polymer their ability to release $\mathrm{Ag}^{+}$will practically not change for the full material life. Furthermore by incorporating silver nanoparticles into polymer matrices, it is possible to create reliable protection against undesirable polymer degradation factors, resulting in a substantial enhancement of the durability of the antimicrobial properties compared to the case in which silver clusters are not 
embedded but only supported by a substrate (chemical or physical adhesion). In fact, in this case, the particles can get easily lost [14] as a consequence of the mechanical action (e.g., washing cycles).

The stabilization of metal nanoparticles in the polymer matrix is essentially affected by the polymer nature and its functional groups. The more the electron donor properties of the polymer functional groups, the stronger is their interfacial adhesion to dispersed phase particles. In the case of polystyrene matrix, the strong interaction of the aromatic electrons with the silver atoms metal surface leads to an enhancement of the stability of the silver nanoparticles in the nanocomposite [15].

\section{Conclusion}

Antimicrobial silver polystyrene nanocomposites have been prepared by dissolving silver 1,5-cyclooctadiene hexafluoroacetylacetonate into amorphous polystyrene and thermally annealing this solid solution for $10 \mathrm{~s}$ at $180^{\circ} \mathrm{C}$. The silver atoms generated during the $[\mathrm{Ag}(\mathrm{hfac})(\mathrm{COD})]$ thermal decomposition clusterize, leading to the formation of a hyperfine dispersion of silver nanoparticles. The obtained silver-doped polystyrene material shows very strong antimicrobial characteristics which are comparable with the antimicrobial activity of a pure micrometric silver powder for silver concentrations in the polymer higher than $30 \%$ by weight.

\section{References}

[1] L. Nicolais and G. Carotenuto, Metal-Polymer Nanocomposites, John Wiley \& Sons, Hoboken, NJ, USA, 2005.

[2] F. Nicolais and G. Carotenuto, "Synthesis of polymer-embedded metal, semimetal, or sulfide clusters by thermolysis of mercaptide molecules dissolved in polymers," Recent Patent on Materials Science, vol. 1, no. 1, pp. 1-11, 2008.

[3] E. Amato, Y. A. Diaz-Fernandez, A. Taglietti et al., "Synthesis, characterization and antibacterial activity against gram positive and gram negative bacteria of biomimetically coated silver nanoparticles," Langmuir, vol. 27, no. 15, pp. 9165-9173, 2011.

[4] P. Pallavicini, A. Taglietti, G. Dacarro et al., "Self-assembled monolayers of silver nanoparticles firmly grafted on glass surfaces: low $\mathrm{Ag}^{+}$release for an efficient antibacterial activity," Journal of Colloid and Interface Science, vol. 350, no. 1, pp. 110 116, 2010.

[5] P. Dallas, V. K. Sharma, and R. Zboril, "Silver polymeric nanocomposites as advanced antimicrobial agents: classification, synthetic paths, applications, and perspectives," Advances in Colloid and Interface Science, vol. 166, no. 1-2, pp. 119-135, 2011.

[6] R. D. Deshmukh and R. J. Composto, "Surface segregation of silver nanoparticles in the in-situ synthesized Ag/PMMA nanocomposites," in Proceedings of the Bulletin of the American Physical Society, Baltimore, Md, USA, March 2006.

[7] C. Damm and H. Münstedt, "Kinetic aspects of the silver ion release from antimicrobial polyamide/silver nanocomposites," Applied Physics A, vol. 91, no. 3, pp. 479-486, 2008.

[8] M. Jokar, R. Abdul Rahman, N. A. Ibrahim, L. C. Abdullah, and C. P. Tan, "Melt production and antimicrobial efficiency of low-density polyethylene (LDPE)-silver nanocomposite film," Food and Bioprocess Technology, vol. 5, no. 2, pp. 719782, 2010.

[9] G. Carotenuto, M. Palomba, A. Longo, S. de Nicola, and L. Nicolais, "Optical limiters based on silver nanoparticles embedded in amorphous polystyrene," Science and Engineering of Composite Materials, vol. 18, no. 3, pp. 187-190, 2011.

[10] D. Pullini, G. Carotenuto, M. Palomba, A. Mosca, A. Horsewell, and L. Nicolais, "In situ synthesis of high-density contact-free Ag-nanoparticles for plasmon resonance polystyrene nanocomposites," Journal of Materials Science, vol. 46, no. 24, pp. 7905-7911, 2011.

[11] A. L. Willis, Z. Chen, J. He, Y. Zhu, N. J. Turro, and S. O’Brien, "Metal acetylacetonates as general precursors for the synthesis of early transition metal oxide nanomaterials," Journal of Nanomaterials, vol. 2007, Article ID 14858, 7 pages, 2007.

[12] M. Berney, F. Hammes, F. Bosshard, H. U. Weilenmann, and T. Egli, "Assessment and interpretation of bacterial viability by using the LIVE/DEAD BacLight kit in combination with flow cytometry," Applied and Environmental Microbiology, vol. 73, no. 10, pp. 3283-3290, 2007.

[13] J. Sjollema, M. Rustema-Abbing, H. C. van der Mei, and H. J. Busscher, "Generalized relationship between numbers of bacteria and their viability in biofilms," Applied and Environmental Microbiology, vol. 77, no. 14, pp. 5027-5029, 2011.

[14] M. Pollini, F. Paladini, A. Licciulli, A. Maffezzoli, L. Nicolais, and A. Sannino, "Silver-coated wool yarns with durable antibacterial properties," Journal of Applied Polymer Science, vol. 125, no. 3, pp. 2239-2244, 2012.

[15] I. R. Kamrupi, P. Phukon, B. K. Konwer, and S. K. Dolui, "Synthesis of silver-polystyrene nanocomposite particles using water in supercritical carbon dioxide medium and its antimicrobial activity," Journal of Supercritical Fluids, vol. 55, no. 3, pp. 1089-1094, 2011. 

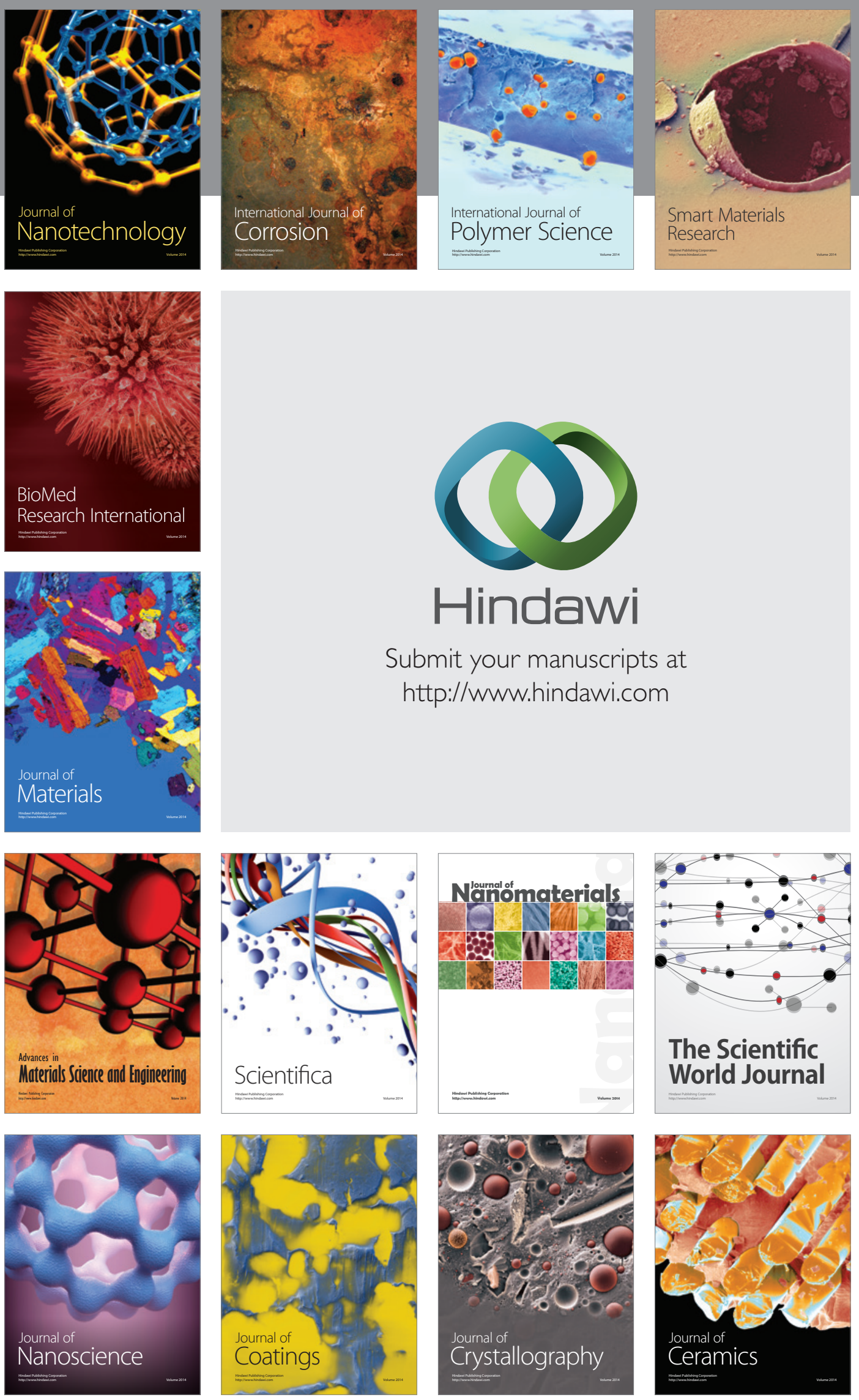

The Scientific World Journal

Submit your manuscripts at

http://www.hindawi.com

\section{World Journal}

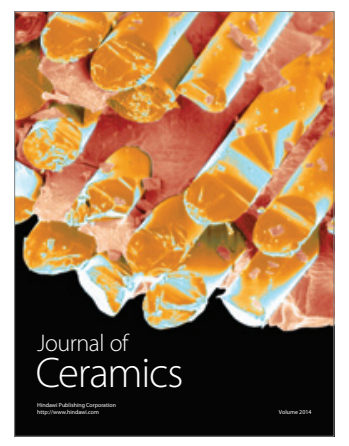

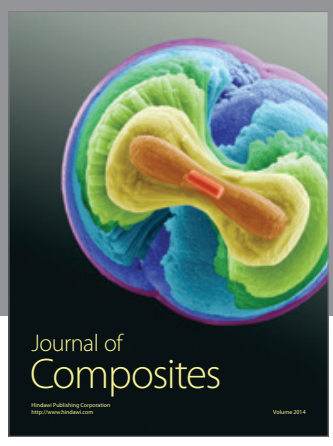
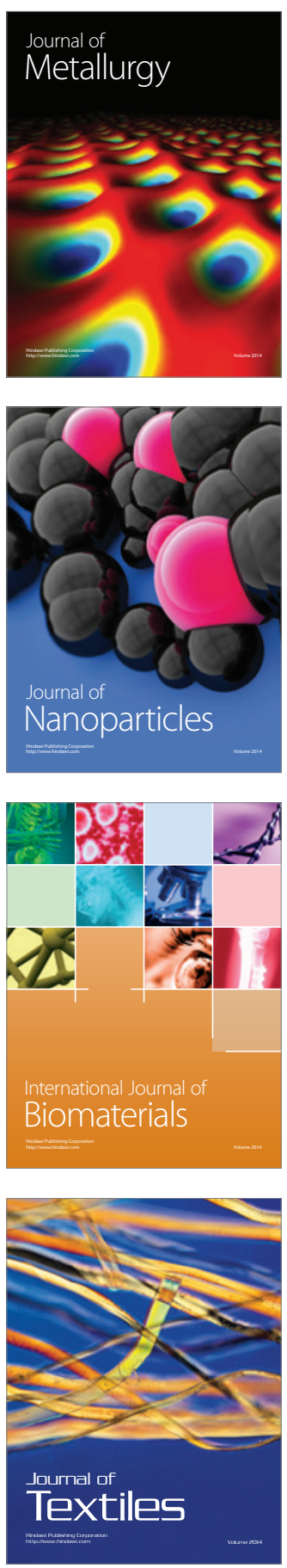